\title{
MÔ PHỎNG VÙNG XÁO TRộN DO LỰC ÉP NGANG KHI THI CÔNG PVD BẰNG PLAXIS 2D
}

\author{
PHAN TRUOÒNG SONN \\ Khoa Kỹ thuật Xây dưng, truoòng đại học Công nghiệp TPHCM; \\ phantruongson@iuh.edu.vn
}

Tóm tắt. PVD (Prefabricated vertical drain) là giải pháp không đắt, có thể thi công dễ dàng trong không gian hạn chế, cung cấp tính dẫn cao, rút ngắn đường thoát cho đất có tính thấm nhỏ và tăng tốc tiến trình cố kết. Mặc dù có những thành công về hiệu dụng, còn có những vấn đề tồn tại với PVD. PVD được đưa vào đất bằng cọc cấy và bịt tấm neo ở mũi. Và sự cấy vào đất này xáo trộn đáng kể vùng đất xung quanh. Ở đó có sự chèn ép kết cấu hạt, gia tăng áp lực lỗ rỗng, giảm hạ độ bền và lượng nước trong vùng bị xáo trộn.

Do tính phong phú về giá trị và sự phụ thuộc vào nhiều yếu tố, bài báo mong muốn mong muốn xác lập hình dạng và phạm vi vùng xáo trộn do lực ép ngang khi thi công PVD được mô phỏng bằng phần tử hữu hạn thông qua phần mềm Plaxis với đặc trưng với nền đất yếu rất phổ biến ở vùng lân cận thành phố Hồ Chí Minh - Việt nam.

Từ khóa. bấc thấm, đất yếu, gia cường nền đất yếu, tính thấm, vùng xáo trộn.

\section{SIMULATION OF THE SMEAR ZONE CAUSED BY HORIZONTAL PRESSURE DURING MANDREL ACTION WITH PLAXIS 2D}

\begin{abstract}
Prefabricated vertical drain is an inexpensive solution that can be easily installed in limited spaces, provides high conductivity, shortens pathways for soils having low permeability, and accelerates the consolidation process. Despite of the success of the product, there are problems with PVD. PVD is brought into the soil by mandrels and anchor plates. And the implantation of this soil greatly disturbed the surrounding soil. There is a compression in the soil texture, increased pore pressure, reduced durability and water content in the smear zone.

Due to the abundance of values and the dependence on many factors, the article desires to establish the shape and extent of the smear zone caused by horizontal pressure during the mandrel action and simulate it by using the finite element through Plaxis software to the soft soil which is very common in the vicinity of Ho Chi Minh City - Vietnam.
\end{abstract}

Keywords.prefabricated vertical drain, soft soil, ground improvement, permeability, smear zone.

\section{DẪN NHẬP - LÝ DO}

\subsection{Lọi ích của PVD}

Khi xây dựng trên nền đất yếu, tải trọng từ các công trình như nên đường, sân bay, đê, nhà xưởng, ... có thể gây lún từ hiện tượng cố kết của các loại đất này. Để tránh các vấn đề nghiêm trọng có thể xảy ra do lún, người ta thường thực hiện tiến trình cố kết sớm và nhanh nhất có thể để đưa công trình vào xây dựng và sử dụng nhanh và an toàn.

Đối với đất có khả năng nén cao, sự cố kết liên quan chặt chẽ với sự đẩy nước ra khỏi đất. Thường, là sự sử dụng giải pháp nén trước hoặc tạo kênh để nước dêิ் dàng thoát ra đối với đất có tính thấm nhỏ như cọc cát. Thời gian gần đây, PVD (prefabricated vertical drain) thường được sử dụng. Đây là giải pháp không đắt, cung cấp tính dẫn cao (hiệu quả hơn 30 lần so với cọc cát có đường kính $300 \mathrm{~mm}$ ), có thể thể thi công dễ dàng trong không gian hạn chế, rút ngắn đường thoát cho đất có tính thấm nhỏ và tăng tốc tiến trình cố kết.

PVD đã và đang được sử dụng nhiều dự án quan trọng như Dự án cải tạo đảo Tân Changi (19922004), New Bangkok International Airport, (1997-2006), dự án mở rộng sân bay Shenzhen (Quảng đôngTrung quốc), tuyến đường sắt giữa Belapur-Seawood-Uran (Mumbai- Ân độ) ... 


\subsection{Hạn chế của PVD}

Mặc dù có những thành công về hiệu dụng, còn có những vấn đề tồn tại với PVD (Akagi 1994; Holtz 1987). PVD được đưa vào đất bằng cọc cấy và bịt tấm neo ở mũi. Và sự cấy vào đất này xáo trộn đáng kể vùng đất xung quanh. Ở đó có sự chèn ép kết cấu hạt, gia tăng áp lực lỗ rỗng, giảm hạ độ bền và lượng nước trong vùng bị xáo trộn (Holtz và Holm 1973). Tính thấm của vùng xáo trộn cũng giảm so với giá trị ban đầu trước khi cấy PVD vào đất (Holtz and Holm 1973). Kết quả là dòng chảy vào PVD bị giảm thấp và tiến trình cố kết bị kéo dài đáng kể.

\subsection{Các nghiên cứu về vùng xáo trộn}

Về cơ bản, vùng xáo trộn quanh PVD được chia làm hai phần: vùng xáo trộn và vùng chuyển tiếp (Bergado et al. 1996; Madhav et al. 1993). Bản chất của sự xáo trộn thì khá phức tạp và phụ thuộc vào nhiều nhân tố như là các đặc trưng của vật liệu đất, hình dạng, độ nhám bề mặt và kích cỡ của cọc cấy, tốc độ cấy và sự dịch chuyển đất sau khi cọc cấy được rút lên (e.g. Onoue et al. 1991, Hird and Moseley 2000).

Khảo sát các nghiên cứu trong phòng thí nghiệm, các đặc trưng không gian của vùng xáo trộn cho thấy mức độ xáo trộn hầu hết được công bố trong vùng lân cận của rãnh thoát nơi nước đi vào và giảm với sự gia tăng khoảng cách hướng tâm từ rãnh thoát (Onoue et al. 1991, Bergado et al. 1991, Madhav et al. 1993, Indraratna and Redana 1998, Hird and Moseley 2000, Sharma and Xiao 2000, Sathananthan and Indraratna 2006).

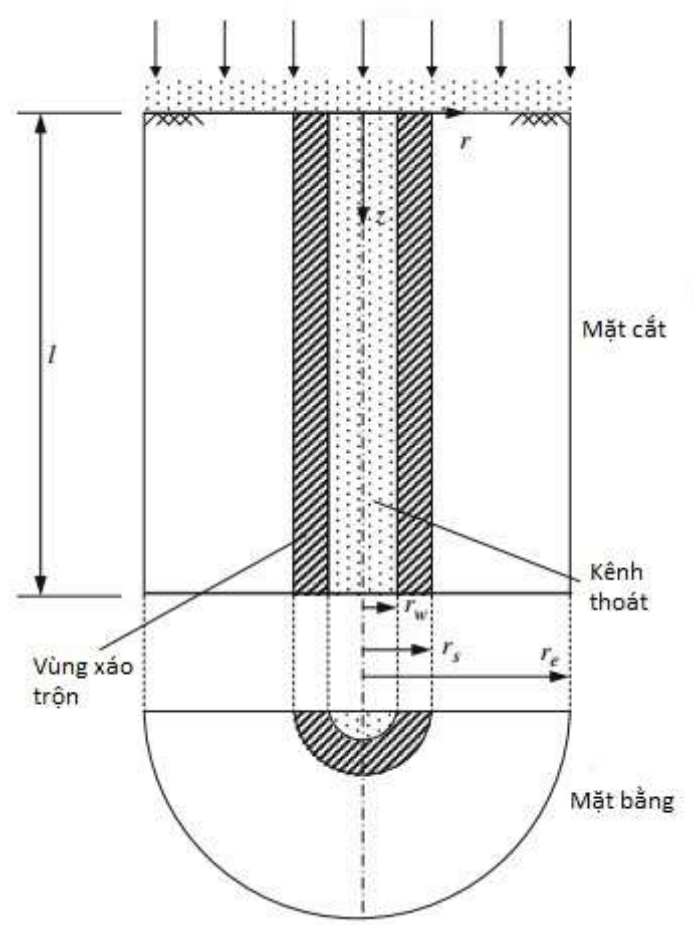

Hình 1: Mô hình PVD.

Vùng chuyển tiếp ở giữa vùng xáo trộn và vùng không xáo trộn (Onoue et al. 1991; Madhav et al. 1993; Indraratna and Redana 1998; Sharma and Xiao 2000) là vùng có sự chuyển tiếp dần tính chất của đất với độ xáo trộn giảm dần theo khoảng cách tăng từ rãnh thoát (Holtz and Holm 1973).

Do vùng xáo trộn có các tiêu chí quan trọng từ đầu vào của một tiến trình tính toán năng lực thoát nước của PVD cũng như các đặc trưng của đất sau khi biến dạng/cố kết, nhiều nhà nghiên cứu đã tiến hành khảo sát kích cỡ và mức độ của vùng xáo trộn. Nghiên cứu của Holtz and Holm 1973, Jamiolkowski et al. 1983, Hansbo 1986, 1987, 1997, Bergado et al. 1991, 1993b, Onoue et al. 1991, Holtz et al. 1991, Mesri et al. 1994, Madhav et al. 1993, and Chai and Miura 1999 đề xuất rằng kích thước của vùng xáo trộn (khoảng cách từ tâm rãnh thoát cho tới biên ngoài của vùng xáo trộn thay đổi giữa 1 đến 4 lần bán kính cọc cấy tương đương $\mathrm{r}_{\mathrm{m} \text {,eq }}$ (mặt cắt ngang của cọc cấy, nếu không phải là hình tròn có thể chuyển đổi 
sang bán kính tương đương $\mathrm{r}_{\mathrm{m} \text {,eq }}$ có cùng diện tích). Các nghiên cứu khác bởi Hansbo 1987; Chai and Miura 1999; Hird and Moseley 2000 đề nghị rằng vùng xáo trộn trong phạm vi từ 2 đến 3 lần $\mathrm{r}_{\mathrm{m}, \mathrm{eq}}$.

Để thiết kế PVD và đánh giá độ cố kết trung bình $(\mathrm{U})$, các mô hình lý thuyết mô tả đặc tính của vùng xáo trộn đã được đề xuất qua nhiều năm. Các mô hình khá đơn giản đầu tiên (Barron 1948, Hansbo 1979) cho rằng một xi lanh đơn vị đất được tháo nước bằng một ống thoát đồng tâm và một vùng xáo trộn với một hằng số độ thấm nằm ngang bị chiết giảm (hình 1). Theo Basu et al. (2006), các nghiên cứu trước đây dựa trên mô hình này đã đề xuất rằng phạm vi của vùng xáo trộn $\left(\mathrm{d}_{\mathrm{s}}\right)$ là từ 2 đến 4 lần đường kính tương đương của $\mathrm{PVD}$ và tính thấm ngang $\left(\mathrm{kh}_{\mathrm{S}}\right)$ giảm từ 2 đến 10 lần tính thấm vùng không xáo trộn $\left(\mathrm{kh}_{0}\right)$, nghĩa là $\mathrm{s}=\mathrm{d}_{\mathrm{s}} / \mathrm{d}_{\mathrm{w}} \sim(2 \div 4)$ và $\kappa=\mathrm{kh}_{0} / \mathrm{kh}_{\mathrm{S}}=(2 \div 10)$. Tuy nhiên, các thí nghiệm trong phòng được trích dẫn chỉ ra rằng phạm vi của vùng xáo trộn có thể lớn hơn như $\mathrm{d}_{\mathrm{s}} / \mathrm{d}_{\mathrm{m}}=9\left(\mathrm{~d}_{\mathrm{m}}\right.$ là đường kính tương đương của cọc cấy).

Các mô hình gần đây đã nỗ lực ghi lại bản chất của vùng xáo trộn sao cho thực tế hơn, mô tả sự biến đổi bên trong vùng xáo trộn (e.g. Walker and Indraratna 2006, Basu et al. 2006, Chung et al. 2009). Hơn nữa, các hiệu ứng còn mang tính thời điểm như là tái cố kết của sét sau khi cấy $\mathrm{PVD}$, ảnh hưởng các đặc trưng của vùng xáo trộn được kết hợp trong những mô hình đã trình bày bởi Indraratna et al. (2005) và Walker et al. (2012).

Việt nam cũng có nhiều nghiên cứu về PVD ở nhiều khía cạnh. Tuy nhiên, xét đến yếu tố thi công làm ảnh hưởng đến vùng xáo trộn cho đến nay chưa thấy. Vì vậy nhu cầu nghiên cứu ở điểm này là hiện hữu và cần thiết để có cái nhìn tổng quan áp dụng hữu hiệu PVD trên nền đất yếu khá phổ biến ở vùng lân cận thành phố Hồ Chí Minh.

\subsection{Mục tiêu của bài báo}

Do tính phong phú về giá trị và sự phụ thuộc vào nhiều yếu tố, bài báo mong muốn mong muốn xác lập hình dạng và phạm vi vùng xáo trộn do lực ép ngang khi thi công PVD được mô phỏng bằng phần tử hữu hạn thông qua phần mềm Plaxis với đặc trưng với nền đất yếu rất phổ biến ở vùng lân cận thành phố Hồ Chí Minh - Việt nam.

\section{CƠ SỞ LẬP LUẬN}

\subsection{Tiến trình thi công $P V D$ và giới hạn nghiên cứu}

- PVD được đưa vào đất bằng măng xông có tiết diện hình chữ nhật 60 x 120. Tốc độ xuyên vào đất được chọn là $600 \mathrm{~mm} / \mathrm{s}$. Tốc độ này phù hợp với thực tế phương tiện và đủ nhanh để tạo tác động ép đất xảy ra như tức thời.

- Trong quá trình đi vào đất, măng xông đâm xuyên ở mũi và ép đất sang phương ngang. Đất bị biến dạng ngang bằng với kích thước của măng xông. Do tốc độ xuyên đất nhanh và thân măng xông thông thường (xuyên lần 2) trơn ướt nên bỏ qua hệ số tiếp xúc giữa đất và thành măng xông.

- Đến độ sâu thiết kế, măng xông rút lên và để PVD lại trong đất.

- Đất yếu sử dụng có tính phổ biến vùng lân cận thành phố Hồ Chí Minh.

\subsection{Công cụ và mô hình tính toán}

\subsubsection{Công cụ}

- Sử dụng phương pháp phần tử hữu hạn thông qua phần mềm Plaxis $2 \mathrm{D}$ với phần tử 16 nút và độ mịn mức khá. 


\subsubsection{Mô hình}

a.

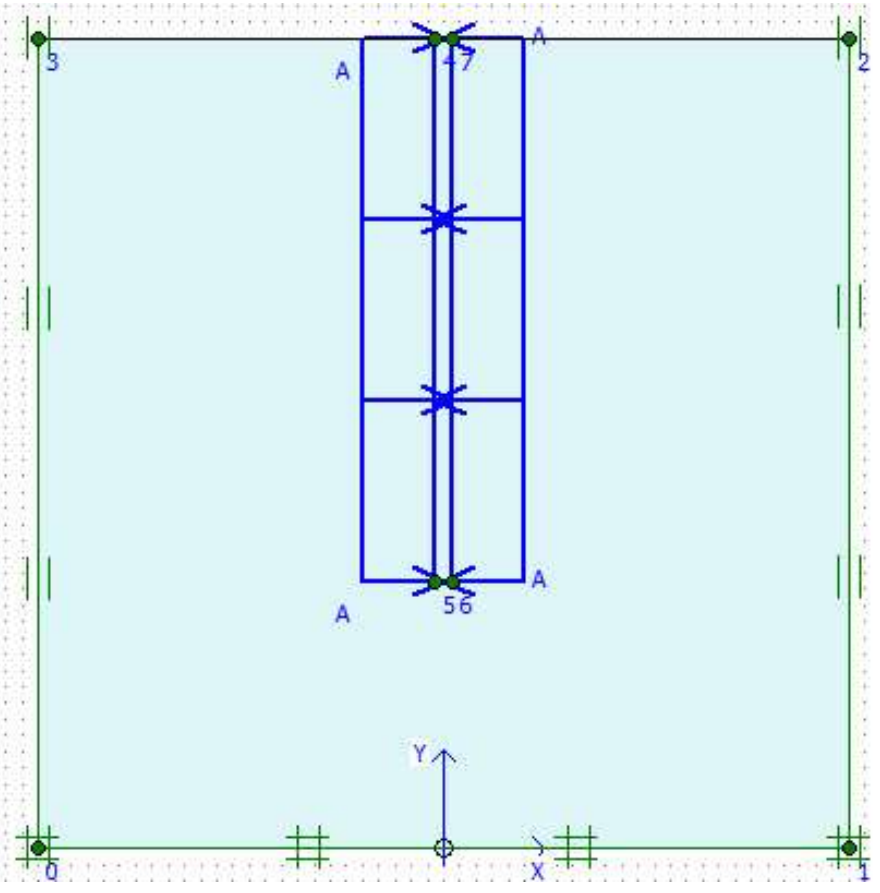

b. Hình 2. Mô hình tính toán

- Để tiết kiệm thời gian tính toán mà vẫn nhận thấy sự biến đổi áp lực nước lỗ rỗng dọc PVD thì chiều dài PVD được sử dụng là $2 \mathrm{~m}$ (20 lần bề rộng PVD).

- Không gian tính toán là $3 \mathrm{~m}$ x $3 \mathrm{~m}$.

- Tiến trình đi vào đất tạo ra áp lực ép đất sang ngang được tính dựa trên lý thuyết biến dạng tương đương của đất. Tương ứng với biến dạng $3 \mathrm{~cm}$ và $6 \mathrm{~cm}$ (đối xứng trục): $\mathrm{p}_{\text {ngang }}=61.6 \mathrm{kN} / \mathrm{m}^{2}$ và $\mathrm{p}_{\mathrm{doc}}=232$ $\mathrm{kN} / \mathrm{m}^{2}$.

- Phạm vi được xác định vùng xáo trộn tập hợp các điểm có áp lực lỗ rỗng bằng không hoặc tiến tới không.

\section{TRƯỜNG HợP TÍNH TOÁN}

\subsection{Số liệu địa chất}

\begin{tabular}{|l|l|l|l|}
\hline \multicolumn{2}{|l|}{ Thành phần hạt } & $:$ & \\
\hline $\begin{array}{l}\text { + Hàm lượng \% hạt sỏi } \\
\text { + Hàm lượng \% hạt cát } \\
\text { + Hàm lượng \% hạt bụi }\end{array}$ & $:$ & 0.00 \\
\hline $\begin{array}{l}\text { + Hàm lượng \% hạt sét } \\
\text { - Độ ẩm tự nhiên }(\mathrm{W} \%)\end{array}$ & $:$ & 19.46 \\
\hline - Dung trọng tự nhiên $\left(\gamma_{\mathrm{w}}, \mathrm{g} / \mathrm{cm}^{3}\right)$ & $:$ & 43.36 \\
\hline - Dung trọng khô $\left(\gamma_{\mathrm{k}}, \mathrm{g} / \mathrm{cm}^{3}\right)$ & $:$ & 54.26 \\
\hline - Dung trọng đẩy nổi $\left(\gamma_{\mathrm{dn}}\right)$ & $:$ & 1.60 \\
\hline - Tỷ trọng $(\Delta)$ & $:$ & 1.04 \\
\hline - Độ bão hòa $(\mathrm{G})$ & $:$ & 0.64 \\
\hline
\end{tabular}




\begin{tabular}{|l|c|l|}
\hline - Độ rỗng $(\mathrm{n})$ & $:$ & 60 \\
\hline - Hệ số rỗng $\left(\mathrm{e}_{0}\right)$ & $:$ & 1.523 \\
\hline - Giới hạn chảy $\left(\mathrm{W}_{\mathrm{L}}\right)$ & $:$ & 51.2 \\
\hline - Giới hạn lăn $\left(\mathrm{W}_{\mathrm{P}}\right)$ & $:$ & 25.6 \\
\hline - Chỉ số dẻo $\left(\mathrm{I}_{\mathrm{P}}\right)$ & $:$ & 25.5 \\
\hline - Độ sệt $(\mathrm{B})$ & $:$ & 1.12 \\
\hline - Hệ số nén lún $\left(\mathrm{a}_{1-2}, \mathrm{~cm}^{2} / \mathrm{kG}\right)$ & $:$ & 0.275 \\
\hline - Mô đun tổng biến dạng $\left(\mathrm{E}_{1-2}, \mathrm{kG} / \mathrm{cm}^{2}\right)$ & $:$ & 4.04 \\
\hline - Góc ma sát trong $\left(\varphi^{\mathrm{o}}\right)$ & $:$ & 4052 \\
\hline - Lực dính $\left(\mathrm{C}, \mathrm{kG} / \mathrm{cm}^{2}\right)$ & $:$ & 0.051 \\
\hline - Hệ số thấm đứng $\left(\mathrm{k}_{\mathrm{v}}, \mathrm{cm} / \mathrm{s}\right)$ & $:$ & 0,000203 \\
\hline - Hệ số thấm ngang $\left(\mathrm{k}_{\mathrm{h}}, \mathrm{cm} / \mathrm{s}\right)$ & $:$ & 0,000203 \\
\hline
\end{tabular}

\subsection{Trường hợp theo phương cạnh dài và trường hợp theo phương cạnh ngắn}

Như mô hình tính toán ở hình 2

\section{KẾT QUẢ VÀ SO SÁNH}

\subsection{Trường hợp theo phương cạnh ngắn}

\subsubsection{Biểu đồ áp lực nước lỗ rỗng}

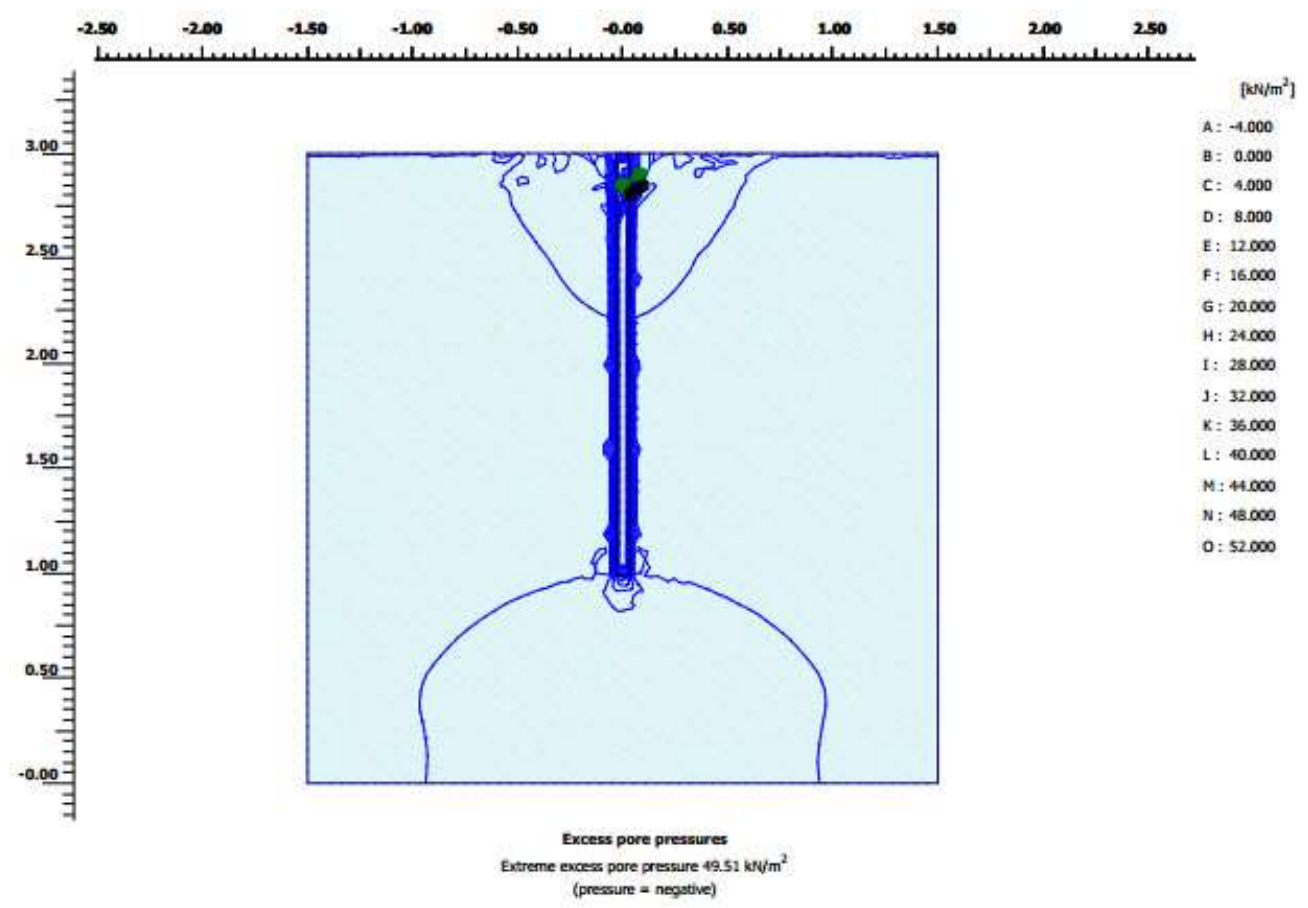

Hình 3: Biểu đồ đường đồng mực áp lực lỗ rỗng $\left(\mathrm{kN} / \mathrm{m}^{2}\right)$ theo phương cạnh ngắn. 


\subsubsection{Thống kê các điểm có áp lụ̣c lỗ rỗng hội tụ về không}

Bảng 1: Tọa độ các điểm có áp lực lỗ rỗng hội tụ về không ở bên trái

\begin{tabular}{|c|c|c|c|c|c|c|c|c|c|c|c|c|c|c|}
\hline $\begin{array}{c}\mathrm{x} \\
(\mathrm{m})\end{array}$ & 0.14 & - & - & - & - & - & - & - & - & - & - & - & - & - \\
\hline $\mathrm{y}$ & & 0.33 & 0.43 & 0.30 & 0.43 & $\mathbf{0 . 4 6}$ & 0.44 & 0.43 & 0.41 & 0.39 & 0.36 & 0.34 & 0.33 \\
\hline$(\mathrm{m})$ & 2.95 & 2.95 & 2.95 & 2.94 & 2.94 & 2.80 & 2.73 & 2.69 & 2.69 & 2.64 & 2.58 & 2.56 & 2.54 & 2.52 \\
\hline $\begin{array}{c}\mathrm{x} \\
(\mathrm{m})\end{array}$ & 0.30 & - & - & - & - & - & - & - & - & - & - & - & - & - \\
\hline $\begin{array}{c}\mathrm{y} \\
(\mathrm{m})\end{array}$ & 2.49 & 0.23 & 0.19 & 0.15 & 0.04 & 0.08 & 0.09 & 0.11 & 0.04 & 0.08 & 0.04 & 0.08 & 0.04 \\
\hline
\end{tabular}

Bảng 2: Tọa độ các điểm có áp lực lỗ rỗng hội tụ về không ở bên phải.

\begin{tabular}{|c|c|c|c|c|c|c|c|c|c|c|c|c|c|c|c|c|c|}
\hline $\mathrm{x}$ & 0.2 & 0.3 & 0.3 & 0.3 & 0.3 & 0.4 & $\mathbf{0 . 4}$ & 0.4 & 0.4 & 0.4 & 0.4 & 0.4 & 0.3 & 0.3 & 0.3 & 0.2 & 0.2 \\
$(\mathrm{~m})$ & 7 & 4 & 1 & 7 & 5 & 4 & 7 & 6 & 6 & 3 & 2 & 0 & 8 & 6 & 3 & 9 & 8 \\
\hline $\mathrm{y}$ & 2.9 & 2.9 & 2.9 & 2.9 & 2.9 & 2.8 & 2.8 & 2.7 & 2.7 & 2.6 & 2.6 & 2.5 & 2.5 & 2.5 & 2.5 & 2.4 & 2.4 \\
$(\mathrm{~m})$ & 9 & 8 & 7 & 3 & 0 & 9 & 5 & 9 & 5 & 6 & 0 & 8 & 6 & 2 & 2 & 8 & 5 \\
\hline $\mathrm{x}$ & 0.2 & 0.2 & 0.2 & 0.2 & 0.1 & 0.1 & 0.0 & 0.1 & 0.1 & 0.0 & 0.0 & 0.0 & 0.0 & 0.0 & 0.0 & 0.1 & 0.1 \\
$(\mathrm{~m})$ & 7 & 1 & 5 & 4 & 7 & 5 & 4 & 2 & 1 & 6 & 9 & 4 & 7 & 4 & 5 & 4 & 1 \\
\hline $\mathrm{y}$ & 2.4 & 2.3 & 2.3 & 2.3 & 2.3 & 2.2 & 2.2 & 2.2 & 2.2 & 2.2 & 2.2 & 2.2 & 2.2 & 2.1 & 1.1 & 1.1 & 1.0 \\
$(\mathrm{~m})$ & 1 & 7 & 6 & 2 & 0 & 7 & 6 & 5 & 5 & 4 & 4 & 1 & 0 & 3 & 8 & 0 & 8 \\
\hline
\end{tabular}

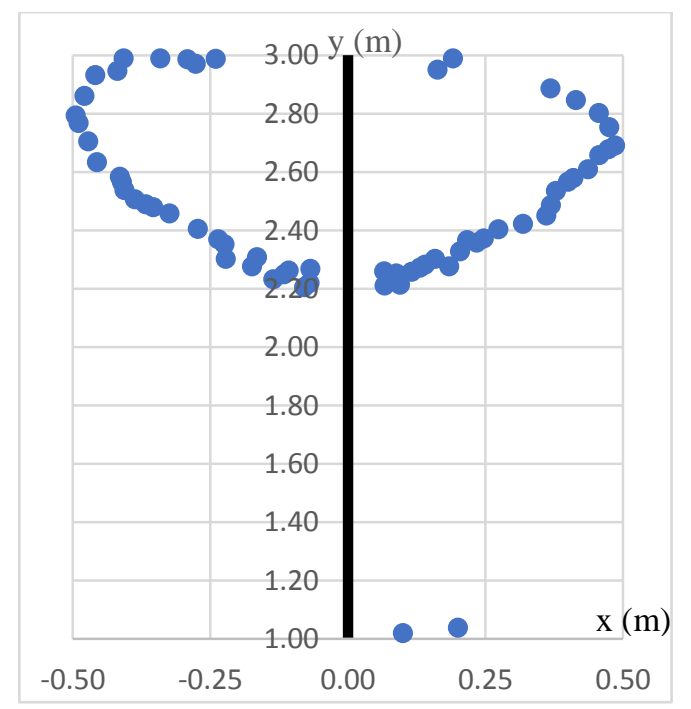

Hình 4: Biểu đồ phân bố các điểm có áp lực lỗ rỗng hội tụ về không theo phương cạnh ngắn. 


\subsection{Trường hợp theo phương cạnh dài}

\subsubsection{Biểu đồ áp lực nước lỗ rỗng}

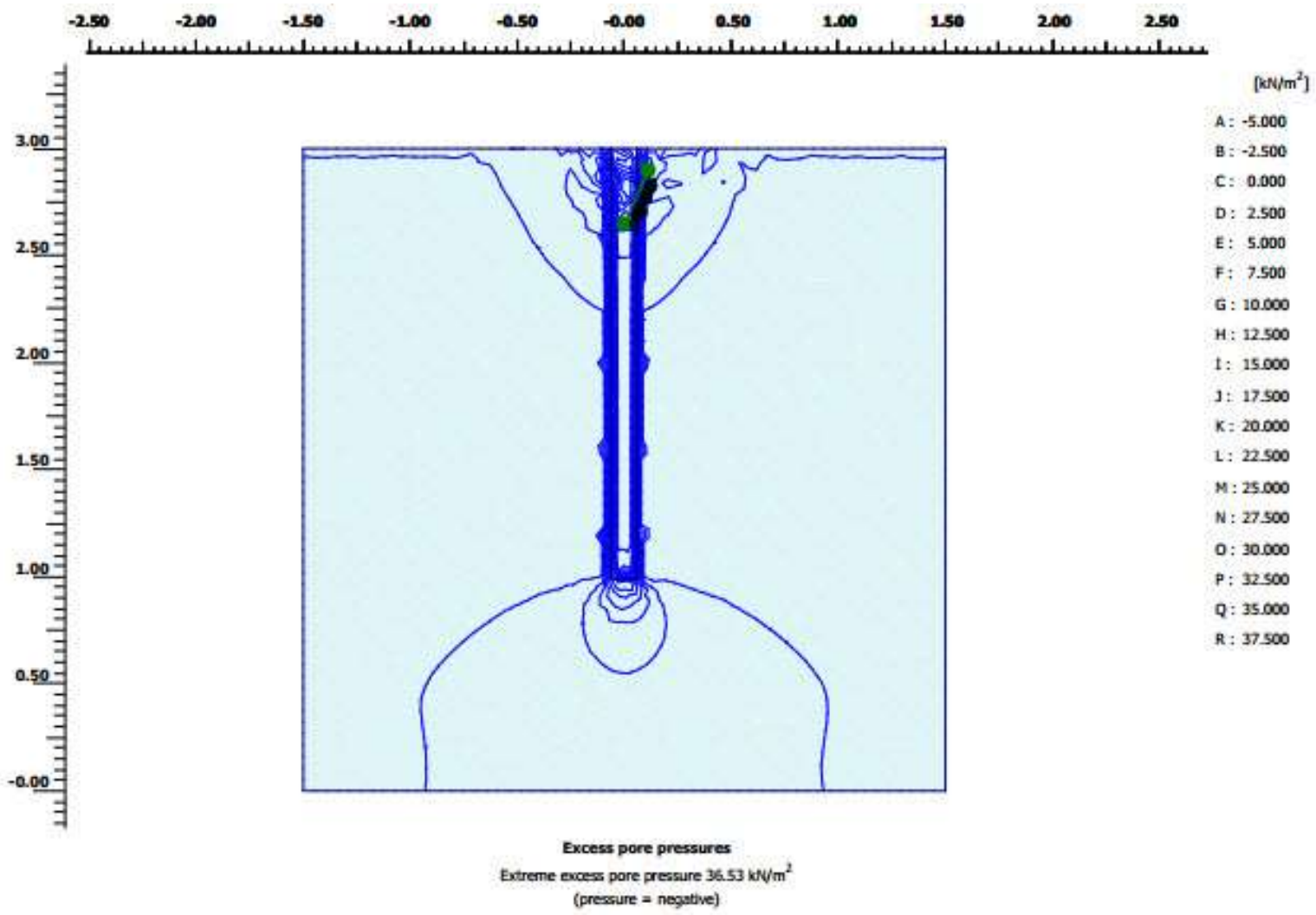

Hình 5: Biểu đồ đường đồng mực áp lực lỗ rỗng $\left(\mathrm{kN} / \mathrm{m}^{2}\right)$ theo phương cạnh dài.

\subsubsection{Thống kê các điểm có áp lực lỗ rỗng hội tụ về không}

Bảng 3: Tọa độ các điểm có áp lực lỗ rỗng hội tụ về không ở bên trái.

\begin{tabular}{|c|c|c|c|c|c|c|c|c|c|c|c|c|c|c|c|}
\hline & - & - & - & - & - & - & - & - & - & - & - & - & - & - & - \\
$\mathrm{x}$ & 0.4 & 0.3 & 0.2 & 0.2 & 0.2 & 0.4 & 0.4 & 0.4 & 0.4 & $\mathbf{0 . 4}$ & 0.4 & 0.4 & 0.4 & 0.4 & 0.3 \\
$(\mathrm{~m})$ & 1 & 4 & 4 & 9 & 8 & 2 & 6 & 8 & 9 & $\mathbf{9}$ & 7 & 6 & 1 & 1 & 9 \\
\hline $\mathrm{y}$ & 2.9 & 2.9 & 2.9 & 2.9 & 2.9 & 2.9 & 2.9 & 2.8 & 2.7 & 2.7 & 2.7 & 2.6 & 2.5 & 2.5 & 2.5 \\
$(\mathrm{~m})$ & 9 & 9 & 9 & 9 & 7 & 5 & 3 & 6 & 9 & 7 & 1 & 3 & 8 & 4 & 1 \\
\hline & - & - & - & - & - & - & - & - & - & - & - & - & - & - & - \\
$\mathrm{x}$ & 0.3 & 0.3 & 0.3 & 0.2 & 0.2 & 0.2 & 0.1 & 0.2 & 0.1 & 0.0 & 0.1 & 0.1 & 0.1 & 0.0 & 0.0 \\
$(\mathrm{~m})$ & 7 & 5 & 2 & 7 & 4 & 2 & 6 & 2 & 7 & 7 & 1 & 2 & 4 & 7 & 8 \\
\hline $\mathrm{y}$ & 2.4 & 2.4 & 2.4 & 2.4 & 2.3 & 2.3 & 2.3 & 2.3 & 2.2 & 2.2 & 2.2 & 2.2 & 2.2 & 2.2 & 2.2 \\
$(\mathrm{~m})$ & 9 & 8 & 6 & 0 & 7 & 5 & 1 & 0 & 8 & 7 & 6 & 5 & 3 & 2 & 1 \\
\hline
\end{tabular}

Bảng 4: Tọa độ các điểm có áp lực lỗ rỗng hội tụ về không ở bên phải.

\begin{tabular}{|c|c|c|c|c|c|c|c|c|c|c|c|c|c|c|c|c|}
\hline $\mathrm{x}$ & 0.1 & 0.1 & 0.3 & 0.4 & 0.4 & 0.4 & $\mathbf{0 . 4}$ & 0.4 & 0.4 & 0.4 & 0.4 & 0.4 & 0.3 & 0.3 & 0.3 & 0.3 \\
$(\mathrm{~m})$ & 9 & 6 & 7 & 1 & 6 & 8 & $\mathbf{9}$ & 7 & 6 & 4 & 1 & 0 & 8 & 7 & 6 & 2 \\
\hline $\mathrm{y}$ & 2.9 & 2.9 & 2.8 & 2.8 & 2.8 & 2.7 & 2.6 & 2.6 & 2.6 & 2.6 & 2.5 & 2.5 & 2.5 & 2.4 & 2.4 & 2.4 \\
$(\mathrm{~m})$ & 9 & 5 & 9 & 5 & 0 & 5 & 9 & 8 & 6 & 1 & 8 & 7 & 3 & 9 & 5 & 2 \\
\hline $\mathrm{x}$ & 0.2 & 0.2 & 0.2 & 0.2 & 0.2 & 0.1 & 0.1 & 0.1 & 0.1 & 0.0 & 0.1 & 0.0 & 0.0 & 0.0 & 0.2 & 0.1 \\
$(\mathrm{~m})$ & 7 & 5 & 2 & 3 & 0 & 6 & 4 & 8 & 3 & 7 & 2 & 9 & 9 & 7 & 0 & 0 \\
\hline $\mathrm{y}$ & 2.4 & 2.3 & 2.3 & 2.3 & 2.3 & 2.3 & 2.2 & 2.2 & 2.2 & 2.2 & 2.2 & 2.2 & 2.2 & 2.2 & 1.0 & 1.0 \\
$(\mathrm{~m})$ & 0 & 7 & 7 & 6 & 3 & 0 & 8 & 8 & 7 & 6 & 6 & 5 & 1 & 1 & 4 & 2 \\
\hline
\end{tabular}




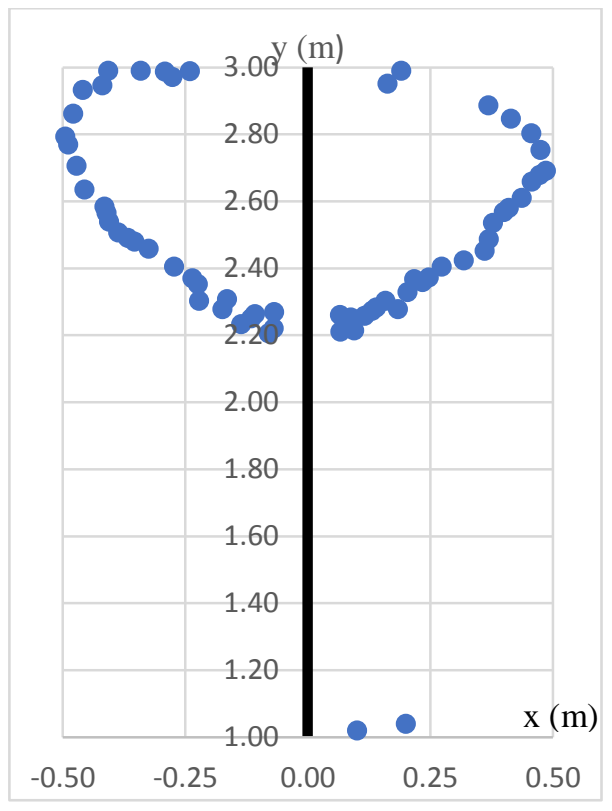

Hình 6: Biểu đồ phân bố các điểm có áp lực lỗ rỗng hội tụ về không theo phương cạnh dài.

\section{NHận XÉT VÀ KÊTT LUậN}

\subsection{Nhận xét}

- Kích thước vùng xáo trộn của đất sét nhão $(\mathrm{B}=1.12 ; \mathrm{Ip}=25.5)$ phát triển từ mặt đất, nơi có độ rỗng lớn, và có xu hướng giảm giá trị theo độ sâu.

- Biên độ miền giá trị của vùng xáo trộn lớn.

- Biên giá trị của hai cạnh là xấp xỉ nhau (cạnh ngắn là $0.47 \mathrm{~m}$; cạnh dài là $0.49 \mathrm{~m})$. Nếu chọn giá trị lớn nhất (bất lợi nhất cho sự tháo nước) của cả hai cạnh thì hình dạng vùng này là xấp xỉ tròn. Điều này phù hợp với giả thiết dạng hình tròn của vùng xáo trộn và sơ đồ bố trí PVD.

- Tỷ lệ $\frac{r_{s}}{r_{m, e q}}=\frac{49}{4.79} \approx 10.2$ khác biệt so với đề xuất của Chai and Miura 1999 và các tác giả $(1 \div 4$ lần); Hansbo 1987; Chai and Miura 1999; Hird and Moseley $2000(2 \div 3$ lần) nhưng sát với các thí nghiệm trong phòng (9 lần).

\subsection{Kết luận}

- Vùng xáo trộn ảnh hưởng bởi nhiều yếu tố nên miền giá trị phong phú gây khó khăn cho việc áp dụng nên nhu cầu khảo nghiệm tại khu vực cự thể là cần thiết.

- Trường hợp khảo sát cho thấy vùng xáo trộn là xấp xỉ tròn, có tỉ số $r_{s} / r_{\text {m.eq }} \sim 10.2$ lớn có khả năng ảnh hưởng nhiều đến khả năng tháo nước và thời gian cố kết trong thực tiễn áp dụng ở vùng lân cận thành phố Hồ Chí Minh.

- Mô phỏng số (FEM) cho thấy là giải pháp đơn giản, nhanh chóng và hiệu quả, được đề xuất sử dụng để tìm giá trị sát với hiện trường, để thiết kế có tính hiệu quả cao hơn.

- Là tiền đề nghiên cứu phạm vi xáo trộn khi áp dụng PVD theo các sơ đồ bố trí khác nhau và đề xuất giải pháp bố trí hiệu quả.

\section{TÀI LIỆU THAM KHẢO}

[1] Buddhima Indraratna1 \& Chamari Bamunawita, Soft clay stabilization by mandrel driven geosynthetic vertical drains, ISSMGE-TC36 WORKSHOP, MEXICO CITY, MAY 2002 (INVITED PAPER).

[2] R. Müller, S. Larsson, Aspects on the modelling of smear zones around vertical drains, Proceedings of the 18th International Conference on Soil Mechanics and Geotechnical Engineering, Paris 2013. 
[3] Indraratna, B., Rujikiatkamjorn, C. \& Ardana, M. (2015). Characterization of smear zone caused by mandrel action. In M. Iskander, M. T. Suleiman, J. Anderson \& D. F. Laefer (Eds.), Geotechnical Special Publication (pp. 2225-2232). United States: American Society of Civil Engineers.

[4] D. Basu, S.M.ASCE1 ; and M. Prezzi, M.ASCE, Effect of the Smear and Transition Zones around Prefabricated Vertical Drains Installed in a Triangular Pattern on the Rate of Soil Consolidation, INTERNATIONAL JOURNAL OF GEOMECHANICS @ ASCE / JANUARY/FEBRUARY 2007.

[5] Tayfun Sengul, Tuncer Edil \& Kutay Ozaydin, Laboratory determination of smear and transition zones due to prefabricated vertical drain installation, Marine Georesources \& Geotechnology, DOI: 10.1080/1064119X.2016.1256924.

[6] Buddhima Indraratna, Recent advancements in the use of prefabricated vertical drains in sof soils, Australian Geomechanics Journal, March issue, 2008, 29-46.

[7] Cholachat Rujikiatkamjorn, Buddhima Indraratna, Design procedure for vertical drains considering a linear variation of lateral permeability within the smear zone, Canadian Geotechnical Journal, vol. 46, no. 3, pp. 270-280, 2009.

[8] Dey, A., Vertical Drains and Smear Effects: A Brief Review, GeoSymposium 2008, 4-5 July, 2008.

[9] A. Parsa Pajouh1,*, B. Fatahi1, and H. Khabbaz, Uncertainties of Smear Zone Characteristics in the Design of Preloading with Prefabricated Vertical Drains, The 4th International Conference on Geotechnical Engineering and Soil Mechanics, November 2-3, 2010, Tehran, Iran.

[10] Báo cáo Địa chất công trình Nhà máy chế biến thủy sản Việt Úc - Công ty CP XD TM \& TK Phương Anh, 15 tháng 5, 2015.

[11] Nguyễn Thị Nụ, Ứng dụng phương pháp xử lý nền đất yếu bằng bấc thấm kết hợp hút chân không và gia tải trước tại nhà máy nhiệt điện Long Phú - Sóc Trăng, Tạp chí Khoa học Kỹ thuật Mỏ - Địa chất Số 55 (2016) trang 46-54.

[12] Nguyễn Hồng Nam, Nguyễn Hồng Trường, Nghiên cứu giải pháp xử lý nền đất yếu bằng thiết bị thoát nước thẳng đứng, Tạp chí Khoa học kỹ thuật Thủy lợi và Môi trường số 30 (9/2010) trang 28-36.

[13] Lê Bá Vinh, Phân tích ảnh hưởng của bấc thấm lý tưởng và bấc thấm không lý tưởng trong mô phỏng xử lý nền bằng phương pháp hút chân không kết hợp với bấc thấm, Tạp chí khoa học và công nghệ thủy lợi số 27 - 2015.

Ngày nhận bài: 29/09/2017

Ngày chấp nhận đăng: 14/04/2018 